\title{
ANALISIS FAKTOR-FAKTOR PENYEBAB KREDIT BERMASALAH PADA BANK NAGARI CABANG LUBUK GADANG
}

\author{
Tari Lara Sinda, Jhon Fernos \\ Akademi Keuangan Dan Perbankan "Pembangunan" Padang \\ tarilarasinda09@gmail.com
}

\begin{abstract}
This study tries to analyze the factors causing non-performing loans at Bank Nagari's Lubuk Gadang branch. There are 2 factors, namely internal and external factors, internal factors, namely factors originating from banks, such as bank negligence in financial analysis, lending regulations, giving credit too easily, increasing the number of staff needed, adding checking as needed, and also help credit beyond the limits while external factors are factors caused from outside the bank, such as business management mismanagement, family debates, research conducted shows factors causing problem loans such as coaching, competition between financial institutions. Debtors are dismissed, bank employees are removed from positions, waiting in arrears, and are billed for family problems.
\end{abstract}

Keyword: the factors causing non-performing loans

\section{PENDAHULUAN}

Perbankan merupakan sektor terpenting untuk membangun suatu perekonomian suatu Negara. Berdasarkan Undang-undang Nomor 10 Tahun 1998 mengenai perbankan, Bank yaitu suatu badan usaha yang menghimpun dana dari masyarakat dalam bentuk simpanan dan menyalurkannya kembali pada masyarakat dalam bentuk kredit atau bentuk lainnya dengan tujuan meningkatkan taraf hidup masyarakat (Ambarsita, 2013).

Peranan perbankan dalam memperbaiki pertumbuhan perekonomian yang ada di Indonesia ini saling dipengaruhi, dalam industri perbankan saat ini masalah yang paling banyak dihadapi adalah masalah dalam pengambilan kredit, sehingga harus mendapatkan perhatian serius.

Kredit sangat diperlukan untuk mendukung perkembangan usaha seseorang, karena dengan menggunakan kredit bisa menambah atau meningkatkan berbagai faktor produksi baik berupa tambahan modal kerja, peningkatan suatu kemampuan sumber daya manusia, dan lainnya. Ada tiga langkah penting yang perlu dikelola secara profesional yaitu kegiatan menghimpun dana yang dikatakan (funding), kemudian menyalurkan dana yang dikatakan (lending), dan jasa-jasa lainnya yang dikatakan (service). Dari kegiatan jasa ini harus diperhatikan secara bersamaan, karena ketiga kegiatan ini saling berkaitan apabila salah satunya tidak dikelola atau dijalankan secara profesional maka dapat mengakibatkan kerugian bagi bank, terutama pada kegiatan funding dan lending yang akan mengalami kerugian

Kegiatan funding merupakan upaya bank untuk menarik dana masyarakat yang berlebihan dan menawarkan produk-produk simpanan dalam bentuk giro, tabungan, deposito, melalui kegiatan funding ini, maka bank mendapatkan modal 
atau dana yang akan dijual kembali kepada masyarakat yang membutuhkan dana.

Kegiatan lending merupakan penyaluran dana yang dihimpun dalam bentuk pinjaman atau kredit. Setiap penyaluran kredit oleh kreditur tentu mengandung resiko, karena adanya keterbatasan kemampuan manusia dalam memprediksi masa yang akan datang, untuk itu bank harus merencanakan sedemikian rupa dan berusaha untuk menekan risiko munculnya penyebab kredit Bermasalah, dan oleh sebab itu pihak bank juga perlu menilai kelayakan usaha dari debitur dan juga di perlukan adanya pengelolaan dan pengawasan, sehingga adanya persamaan usaha perbankan itu terahasiakan.

Dalam penyaluran kredit kepada masyarakat tidak keseluruhan dana yang disalurkan tersebut dapat dikembalikan seluruhnya atau sebagaimana mestinya, maka hal inilah yang menjadi penyebab-penyebab kredit bermasalah. Kredit bermasalah dapat di artikan sebagai ke tidak sanggupan debitur untuk melunasi pinjamannya kepada bank berupa angsuran pokok dari pinjaman beserta bunganya,serta biaya lainnya di mana mengalami kegagalan karena deviasi (penyimpangan) sehingga tidak sesuai dengan perjanjian yang telah di sepakati yang akhirnya dapat membawa kerugian pada Bank Nagari Cabang Lubuk Gadang.

Kredit bermasalah timbul tidak dengan seketika, melainkan secara bertahap dimana terjadi berbagai penurunan aspek yang dimiliki debitur yang berakhir dengan ketidak mampuan debitur membayar kreditnya. Mencari penyebab kredit macet adalah sulit, karena ada banyak faktor-faktor yang mempengaruhi baik dari sifat intern maupun ekstern. Faktor ekstern "berasal dari luar perusahaan "seperti keadaan ekonomi, persaingan bencana alam dan dari debitur itu sendiri. Sedangkan faktor intern "berasal dari dalam pihak perusahaan" seperti kesalahan penilaian dalam memberikan kredit atau minimnya pengawasan dan pembinaan terhadap kredit yang disalurkan. Kredit bermasalah disebabkan berbagai faktor yang berkaitan antara satu sama lainnya, untuk itu harus segera mungkin mendapatkan penyelesaian. karena dapat menyebabkan terganggunya kondisi bank.

Bank Nagari Cabang Lubuk Gadang dengan segala kepemilikannya memberikan fasilitas kredit kepada masyarakat. Dengan kemudahan yang ditawarkan oleh bank tidak sedikit masyarakat melakukan pengembalian yang tidak sesuai dan terkadang malah menjadi bermasalah. Berikut data kredit yang masyarakat melakukan pengembalian yang tidak sesuai dan terkadang malah menjadi bermasalah. Berikut data kredit yang masyarakat melakukan pengembalian yang tidak sesuai dan terkadang malah menjadi bermasalah. Berikut data kredit yang tersalurkan sesuai kegunaan pada bank Nagari Lubuk Gadang.

\section{Tabel 1}

Kredit Bermasalah Pada

Bank Nagari Cabang Lubuk Gadang

Tahun 2017-2019

( Dalam Rp.000)

\begin{tabular}{|l|c|c|c|c|}
\hline No & Tahun & Kurang Lancar & Diragukan & Macet \\
\hline 1 & 2017 & 150.433 & 121.017 & 697.376 \\
\hline 2 & 2018 & 7.572 & 64.906 & 763.146 \\
\hline 3 & 2019 & 124.137 & 0 & 542.882 \\
\hline & Total & 282.142 & 186.013 & 2.003 .404 \\
\hline
\end{tabular}


Sumber: Bank Nagari Cabang lubuk gadang

Pada tabel 1 diatas terlihat jumlah kredit kurang lancar sebesar Rp. 150.433 turun menjadi Rp. 7.572 pada tahun 2018 kemudian naik menjadi Rp. 124.137 pada tahun 2019. Kredit diragukan Rp. 121.017 turun menjadi 64.906 pada tahun 2018 dan pada tahun 2019 tidak ada terjadi hutang yang diragukan. Pada tahun 2017 kredit macet sebesar Rp. 697.376 naik menjadi 763.146 pada tahun 2018 kemudian turun menjadi Rp. 542.882 pada tahun 2019. Hal ini disebabkan oleh rendahnya pendapatan nasabah, yang artinya jika pendapatanya rendah maka kemampuannya dalam membayarkan kredit juga rendah. Pada tahun 2017 ini kredit kurang lancar paling tinggi. Dalam hal ini kredit yang di salurkan Bank Nagari Cabang Lubuk Gagang. Masalah yang dialami nasabah sebabkan oleh merosotnya perekonomiaan, yang mengakibatkan lingkungan pengusaha dalam membayar angsuran pokok pinjaman mengalami masalah sehingga menyebabkan kredit lancar menjadi kurang lancar, diragukan, bahkan macet. Selain kredit yang meningkatnya dalam masyarakat khususnya di masyarakat menengah keatas banyak pihak bank yang melakukan penyimpangan dari aturan untuk pemberian kredit, karena persaingan kredit yang terlalu teliti dalam mencari nasabah. Selain itu banyak karyawan bank lalai dalam mengnalisis pemberian kredit dan pemberian jumlah yang tidak sesuai dengan kemampuan nasabahnya sehingga terjadilah kredit macet. Mengingat demikian pentingnya kegiatan perkreditan bagi perbankan dimana ke gagalan yang terjadi pada perkreditan dapat mengakibatkan bank tersebut tidak sehat. Pencabutan izin usaha yang di lanjutkan dengan likuidasi atas 16 buah bank pada tanggal 1 november 1997, disebabkan oleh banyaknya kredit bermasalah (non performing loans) yang sangat sulit di selesaikan.

Hal ini di picu pula oleh pelanggaran atas ketentuan-ketentuan atau ramburambu perkreditan yang di tetapkan Bank Indonesia. Penyebab utama dari semua kejadian-kejadian tersebut adalah karena banyaknya kredit macet yang di sebabkan oleh pelanggaran-pelanggaran terhadap ketentuan-ketentuan tentang pedoman kebijakan perkreditan bank. Sesuai dengan kejelasan UU No.7 Tahun 1992 tentang perbankan ditegaskan bahwa "kredit yang diberikan oleh bank mengandung resiko, sehingga dalam pelaksanaannya bank harus dapat memperhatikan asas-asas perkreditan yang sehat". Agar pemberian kredit dapat dilakukan secara konsisten dan asas perkreditan yang sehat sehingga setiap bank diwajibkan membuat suatu kebijakan perkreditan secara tertulis yang dapat digunakan sebagai pedoman. Kredit bermasalah memberikan dampak yang kurang baik bagi Negara masyarakat dan perbankan Indonesia.

Adanya rentang waktu pengembalian pinjaman menimbulkan resiko yang sangat besar yang ditanggung oleh bank terhadap ketidakpastian pengembalian pinjaman dari debitur. Dengan adanya SK Direksi Bank Indonesia No.27/162/KEP/DIR tanggal 31 maret diharapkan dalam pemberian kredit dapat disesuaikan dengan kebutuhan sehingga tidak terjadinya kredit macet serta dapat mnyelesaikan kredit bermasalah yang telah terjadi.

Berdasarkan uraian di atas maka penulis tertarik untuk membuat judul tugas akhir dengan judul Analisis Faktor-Faktor Penyebab Kredit Bermasalah Pada Bank Nagari Lubuk Gadang. Sesuai dengan judul dan pembahasan latar belakang yang telah disajikan sebelumnya, sebagai badan usaha yang bergerak menghimpun dana dari masyarakat dan menyalurkan dana tersebut dalam bentuk kredit pada Bank Nagari Lubuk Gadang. Tentunya peranan mengelola dalam mengurangi 
resiko yang akan terjadi, untuk lebih terarahnya tugas akhir ini, maka rumusan masalahnya bagaimana analisis faktor-faktor penyebab kredit bermasalah pada bank nagari cabang Lubuk Gadang. maka penulis tertarik melakukan penelitian dalam bentuk Tugas Akhir dengan judul: Analisa Faktor-Faktor Penyebab Kredit Bermasalah Pada Bank Nagari Cabang Lubuk Gadang.

\section{METODE PENELITIAN}

Dalam pengumpulan data dan bahan untuk melakukan penelitian ini, digunakan metode-metode sebagai berikut :

\section{Metode Pengumpulan Data}

a. Studi Lapangan (FieldResearch)

Peninjauan langsung ke objek penelitian, yaitu melakukan wawancara langsung dengan pihak bank untuk meneliti hasil data primer dan membantu melengkapi data yang diperlukan.

b. Studi Kepustakaan (Library Research)

Studi kepustakaan dilakukan untuk memperoleh tulisan-tulisan dan informasi yang berhubungan dengan pembahasan yang bersangkutan.

\section{Metode Analisis Data}

Adapun metode analisis data yang digunakan adalah metode kualitatif dan kuantitatif. Dimana metode kualitatif merupaka metode yang dilakukan untuk mendapatkan informasi terkait melalui wawancara terhadap PT. Bank Nagari Cabang Lubuk Gadang dan menggunakan metode kuantitatif, yaitu metode yang digunakan untuk melakukan perhitungan data dalam bentuk tabel.

\section{HASIL DAN PEMBAHASAN \\ Perkembangan Kredit Bermasalah Pada Bank Pembangunan Daerah Sumatera Barat Cabang Lubuk Gadang}

Tabel. 2

Tingkat Pertumbuhan Kredit Bermasalah

Pada Bank Pembangunan Daerah Sumatera Barat

Cabang Lubuk Gadang

Tahun 2017 -2019

( Dalam Rp.000 )

\begin{tabular}{|c|c|r|c|}
\hline No & Tahun & \multicolumn{1}{|c|}{ Jumlah } & $\begin{array}{c}\text { Tingkat Pertumbuhan } \\
(\boldsymbol{\%})\end{array}$ \\
\hline 1 & 2017 & 284.142 & 0 \\
\hline 2 & 2018 & 185.924 & 34,56 \\
\hline 3 & 2019 & 2.003 .404 & 977,54 \\
\hline
\end{tabular}

Sumber : Bank Pembangunan Daerah Sumatera Barat Cabang Lubuk

Gadang,data olahan

Dari tabel di atas pada tahun 2017 s/d tahun 2018 laju pertumbuhan kredit bermasalah adalah sebesar 34,56\% kemudian pada tahun 2018 s/d tahun 2019 tingkat pertumbuhan kredit bermasalah naik menjadi 977,54\%

Jika pertumbuhan kredit bermasalah terus meningkat tiap tahunya maka bank akan mengalami kerugian, hal ini disebabkan karena banyaknya nasabah yang menunggak dan sisi agunan yang tidak sesuai dengan kredit yang dipinjam.

Penyebab Kredit Bermasalah Pada Bank Pembangunan Daerah Sumatera Barat Cabang Lubuk Gadang

Kredit bermasalah atau non performing loan (NPL), menjadi salah satu penyakit 
yang bisa menghambat perkembangan sektor jasa keuangan. Apa yang menjadi penyebab terjadinya hal tersebut. Kredit bermasalah disebabkan oleh berbagai faktor, baik faktor internal maupun eksternal.

a. Faktor internal

Penyebab timbulnya kredit bermasalah adalah penyimpangan dalam pelaksanaan prosedur perkreditan, itikad kurang baik dari pemilik, pengurus, atau pegawai bank, lemahnya sistem administrasi dan pengawasan kredit serta lemahnya sistem informasi kredit bermasalah. Berdasarkan permasalahan terkait dengan ini yang terjadi di Bank Nagari Lubuk Gadang terlihat bahwa:

1) Jaringan yang sering bermasalah terkait dengan pengelolaan sistem kreditur.

2) Lemahnya sistem administrasi oleh petugas bank terkait dengan kredit.

3) Kerja petugas bank kurang teliti dalam memilih calon nasabah kredit sehingga sering terjadi keterlambatan pembayaran kredit.

4) Kinerja petugas bank pada bagian kredit masih belum efektif, dan Kekurangmampuan petugas bank dalam mengelola kredit.

b. Faktor eksternal oleh :

Faktor eksternal penyebab terjadinya kredit bermasalah yaitu disebabkan

1) Kelemahan dalam analisa kredit, ini bisa disebabkan oleh berbagai hal di antaranya yaitu lemahnya kebijakan dan SOP analisa kredit.

2) Asal ada agunan, bank hanya melihat agunan sebagai dasar keputusan pemberian kredit, sehingga faktor-faktor analisa yang lainnya terabaikan.

3) Realisasi kredit yang tidak tepat waktu, keputusan dan pencairan kredit yang terlalu lama, menyebabkan nasabah tidak dapat mengalokasikan dananya sesuai dengan kebutuhannya.

4) Plafon kredit yang tidak sesuai kebutuhan nasabah. Plafon kredit yang terlalu kecil menyebabkan nasabah tidak dapat menggunakan dananya dengan optimal, sehingga mungkin akan menghambat usahanya. Sedangkan plafon kredit yang terlalu besar menyebabkan nasabah tidak dapat memenuhi kewajibannya.

\section{Upaya penanganan kredit Bermasalah pada Bank Nagari Cabang Lubuk}

\section{Gadang}

a. Debitur dalam kategori kredit perhatian khusus, dilakukan melalui telepon atau sms, agar nasabah segera memenuhi kewajibannya supaya tidak terkena denda dan tidak membengkaknya hutang.

b. Debitur dalam kategorikredit kurang lancar, akan diberikan Surat Peringatan Pertama(SP 1) kepada debitur.

c. Debitur dalam kategori kredit diragukan, akan diberikan Surat Peringatan Kedua (SP II) kepada debitur.

d. Debitur dalam kategori kredit macet, akan diberikan Surat peringatan terakhir (SP III) kepada debitur.

e. Jika sampai dikeluarkannya SP III debitur tidak menanggapinya, maka pihak Bank akan melakukan menarikan barang agunan. Barang agunan yang ditarik akan dilelang untuk pelunasan hutang debitur dan biaya yang di tumbulkan. Apabila dana tersebut berlebih maka akan di kembalikan kepada debitur.

\section{PEMBAHASAN}

Pada tahun 2017 s/d tahun 2018 laju pertumbuhan kredit bermasalah adalah sebesar 34,56\% kemudian pada tahun 2018 s/d tahun 2019 tingkat pertumbuhan kredit bermasalah naik menjadi 977,54\% 
Jika pertumbuhan kredit terus meningkat tiap tahunya maka bank akan mengalami kerugian, hal ini disebabkan karena banyaknya nasabah yang menunggak dan sisi agunan yang tidak sesuai dengan kredit yang dipinjam.

Kredit bermasalah disebabkan oleh berbagai faktor, baik faktor internal maupun eksternal, faktor internal yaitu faktor yang berasal dari dalam bank, seperti keteledoran bank mematuhi peraturan pemberian kredit, terlalu mudah memberikan kredit, kurangnya jumlah staf yang berpengalaman, kurangnya analisis terhadap nasabah, dan juga pemberian kredit yang melampaui batas, sedangkan faktor eksternal yaitu faktor yang disebabkan dari luar bank, seperti adanya salah urus pengelolaan usaha, permasalahan keluarga contohnya kematian, perceraian, dan lainlain. Kesulitan likuiditas keuangan suatu perusahaan, kejadian diluar kekuasaan debitur contohnya bencana alam, perang dan juga watak buruk seorang debitur.

\section{SIMPULAN}

Berdasarkan uraian tentang faktor kredit bermasalah maka yang menjadi permasalahan ini adalah Bagaimana Analisis Faktor-Faktor Penyebab Kredit Bermasalah Pada Bank Nagari Cabang Lubuk Gadang. Ada 2 faktor-faktor yaitu faktor internal dan faktor eksternal, faktor internal yaitu faktor yang berasal dari dalam bank, seperti keteledoran bank dalam menganalisa nasabah, peraturan pemberian kredit, terlalu mudah memberikan kredit, kurangnya jumlah staf yang berpengalaman, kurangnya analisis terhadap nasabah, dan juga pemberian kredit yang melampaui batas, sedangkan faktor eksternal yaitu faktor yang disebabkan dari luar bank, seperti adanya salah urus pengelolaan usaha, permasalahan keluarga contohnya kematian, perceraian, dan lain-lain. Kesulitan likuiditas keuangan, kejadian diluar kekuasaan debitur contohnya bencana alam, perang dan juga watak buruk seorang debitur.

\section{UCAPAN TERIMA KASIH}

Penulis mengucapkan terimah kasih kepada:

1. Kedua orang tua yang senantiasa memerawat dan mendidik serta mencurahkan kasih dan sayangya pada penulis

2. Direktur AKBP beserta prodi AKBP serta bapak ibu dosen yang telah mendidik dan memberikan ilmu pengetahuan kepada penulis.

3. Pimpinan PT. BPD Sumatera Barat yang telah mengizinkan penulis memperoleh informasi

4. Serta semua pihak yang telah membantu penulis dalam penyelesaian artikel ini.

\section{DAFTAR PUSTAKA}

Ambarsita, L. (2013). Analisis Penanganan Kredit Macet. Manajemen Bisnis, 3(1), $15-20$.

Alanshari, F., \& Marlius, D. (2018). Prosedur Pemberian Kredit KPR Pada PT. Bank Tabungan Negara (Persero) TBK Cabang Pembantu Bukittinggi. https://doi.org/10.31227/osf.io/rsfhc

Amelia, L., \& Marlius, D. (2018). Pengendalian Kredit Dalam Upaya Menciptakan Bank Yang Sehat Pada PT. Bank Pembangunan Daerah Sumatera Barat Cabang Utama Padang. https://doi.org/10.31227/osf.io/kpc64

Anisa, W. G. (2012). Analisis Faktor yang Mempengaruhi Penungkapan Manajemen Risiko. Skripsi FAKULTAS EKONOMIKA DAN BISNIS UNIVERSITAS DIPONEGORO SEMARANG, 22.

Dedi Mulyadi. (2016). Analisis Manajemen Kredit Dalam Upaya Meminimalkan 
Kredit Bermasalah. Jurnal Manajemen \& Bisnis Kreatif, 1(1), 1-24. repository.ubpkarawang.ac.id

Ekonomika, F., Bisnis, D. A. N., \& Diponegoro, U. (2014). Kredit Bermasalah Pada Bank Umum.

Ilham Febriansyah, A. (2019). Penyelesaian Kredit Bermasalah PT. Bank Pembangunan Daerah (BPD) Sumbar Cabang Alahan Panjang Kabupaten Solok Ilham Febriansyah, Afriyeni. Akademi Keuangan Dan Perbankan, 1-14. https://osf.io/preprints/vutmj/

Ismail. (2010). akuntansi bank (cetak ke-1). jakarta.

Ikbal, M., \& Marlius, D. (2017). Pengaruh Jumlah Taksiran Dan Uang Pinjaman Terhadap Laba Bersih Pada PT. Pegadaian (UPC) Gurun Laweh. https://doi.org/10.31227/osf.io/uch4a

Kasmir. (2014). Bank Dan Lembaga Keuangan Lainnya. Edisi Revisi 2014 PT Raja Grafindo Persada Jakarta.

Kpr, R., Bank, P., Cabang, S., Kendari, U., Sultra, B., Utama, C., \& Dibimbing, K. (2019). ABSTRAK Rahmawati 2019. :

Mendari, W. E., \& Widayati, R. (n.d.). Upaya Penanganan Kredit Bermasalah Pada Bank Nagari Cabang Utama Padang. 1-12.

Yulita, A. (2014). Analisis Pengaruh Faktor Makroekonomi Terhadap Tingkat Kredit Bermasalah Pada Bank Umum Di Indonesia. 